\title{
Functional somatic symptoms in patients with major depressive disorder in a tertiary care hospital
}

\author{
Fenil Shah ${ }^{1}$, Bhaveshkumar M. Lakdawala ${ }^{2}$, Vaishal N. Vora ${ }^{3}$, Manasvi V. Jariwala ${ }^{4}$ \\ Vihang Patel $^{5}$, Sandeep Grover ${ }^{6}$, Ajit Avasthi ${ }^{7}$ \\ ${ }^{1}$ Resident Doctor, Department of Psychiatry, AMC-MET Medical College, Ahmedabad, Gujarat, India. \\ ${ }^{2}$ Professor and Head, Department of Psychiatry, AMC-MET Medical College, Ahmedabad, Gujarat, India. \\ ${ }^{3}$ Associate Professor, Department of Psychiatry, AMC-MET Medical College, Ahmedabad, Gujarat, India. \\ ${ }^{4}$ Assistant Professor, Department of Psychiatry, AMC-MET Medical College, Ahmedabad, Gujarat, India. \\ ${ }^{5}$ Resident Doctor, Department of Psychiatry, AMC-MET Medical College, Ahmedabad, Gujarat, India. \\ ${ }^{6}$ Professor, PGIMER, Chandigarh, India. \\ ${ }^{7}$ Professor and Head, Department of Psychiatry, PGIMER, Chandigarh, India.
}

Corresponding author: Manasvi V. Jariwala

Email -dr_bmlakdawala@yahoo.co.in

\begin{abstract}
Background: Functional somatic symtpoms are common in patients with major depressive disorder. The aim of the research was to study the prevalence and typology of Functional Somatic Symptoms (FSS) in patients with depression.

Methodology: A total of 50 patients participated in the study. They were assessed on Bradford Somatic Symptom inventory for Functional Somatic Symptoms (FSS), Beck Depression Inventory (BDI) for severity of depression, and Comprehensive Psychopathological Rating Scale- anxiety index (CPRS-AI) for anxiety symptoms.

Results: The mean age of the study sample was 41.36 years (SD-12.79). Gender distribution was gender distribution (male - $60 \%$ vs. females $40 \%$ ). Majority of the symptoms were found in married (84\%), Hindus $(92 \%)$, and from nuclear family (58\%). A more than half of the patients were from urban background (76\%). The mean duration of illness at the time of assessment was 36 months. As per BDI severity score $36 \%$ have mild, $38 \%$ have moderate and $26 \%$ have severe depression. Total mean CPRS-AI is $(8.78 \pm 4.46)$. The more common FSS as assessed on Bradford Somatic Inventory were severe headache (88\%), feeling tired when not working (86\%), lack of energy (weakness) much of the time (84\%), pain in legs (82\%), aches and pains all over the body $(72 \%)$, mouth or throat getting dry $(72 \%)$, head feeling heavy $(70 \%)$, head feeling hot or burning $(68 \%)$, pain or tension in neck and shoulder $(66 \%)$, low back trouble $(66 \%)$ and sweating a lot $(64 \%)$. The prevalence and typology of FSS was to a certain extent influenced by the sociodemographic variables and severity of depression.

Conclusion: Functional somatic symptoms are highly prevalent in depressed patients and hence deserve more attention while diagnosing depression.
\end{abstract}

Keywords: Depression, Functional somatic symptoms, BSI, BDI, CPRS-AI

(Paper received $-1^{\text {st }}$ December 2020, Peer review completed $-2^{\text {nd }}$ January 2021)

(Accepted $-8^{\text {th }}$ January 2020)

\section{INTRODUCTION}

Functional Somatic Symptoms (FSS) (Physical Symptoms without a known medical explanation) are much common in our healthcare system [1-2]. Approximately one third of patients in primary health care suffer from multiple somatic symptoms leads the main reason for consultation [1]. FSS are linked to depression, anxiety disorders and social stress. Studies done in primary care settings suggest that approximately 66 to $73 \%$ of patients with FSS have depression and anxiety. Patient having multiple somatic complaints are more 
likely to suffer from a poor patient-doctor relationship, Patient are less satisfied with treatment, and more often feel they are not being taken seriously by the doctor [3-4]. If depressed patients seek help for physical symptoms, their depression diagnosis is often delayed as is treatment as they got treatment for only physical symptoms [5]. Furthermore, concurrent somatic symptoms can be a marker for a depressive disorder with higher severity and worse prognosis [6-8]. Depressed patients with functional somatic symptoms respond less often to medical treatment, and they reach complete remission without symptoms less frequently [9-12]. Somatic symptoms were very much more common among adolescents suffering from depressive disorders. Functional somatic symptoms in depression marked a subgroup with increased severity. FSS are known to increase the burden and disability associated with depression. Increased symptomatic burden of FSS in patients with depression also leads to increased utilization of healthcare services, more financial burden and contributes greatly to the recurrence of another new depressive episode there-after [2, 4-10]. Studies done in patients with depression presenting to different treatment settings like primary care, medical outpatient, and psychiatric outpatient clinics suggest high prevalence of FSS across various treatment setting. Studies from different parts of the world have also described the pattern and various typology of FSS in depression suggested that painful symptoms are highly prevalent in patients having depression. There are Very few studies from India which focused on FSS in patients having depression. FSS many times play crucial role in Diagnosis of depression, dominates whole illness to certain extent [11]. The aims of the current study were to study the prevalence and typology of functional somatic symptoms in patients with depressive disorder and to study the socio-demographic and clinical profile of patients with Depressive disorder having functional somatic symptoms. It also aimed to examine the correlation between severity of depression and functional somatic symptoms.

\section{METHODOLOGY}

The study was conducted on fifty consecutive patients with major depressive disorder from out-patient and in-patient sections. It was a cross-sectional study with study duration of 6 months (Jan. 2019-Sept. 2019).

Inclusion Criteria were:

- Age between 16 to 65 years.

- Duration of depression of at least 1 month.

- Patients fulfilling the criteria for Major Depressive Disorder as per DSM-5 criteria.

- Patient having at least one functional somatic complaint as per Bradford Somatic Inventory.

- Patient providing informed consent.

\section{Exclusion Criteria were:}

- Diagnosis of depression with psychotic symptoms \& Other co morbid psychiatric illness.

- Presence of physical illness which could explain the reported somatic complaints.

- Substance use disorders including heavy smoking (20-40 cigarettes/day).

- Chronic, debilitating physical illness like, diabetes, hypertension, end stage organ failure.

- Patient not providing informed consent \& not willing to participate in study.

- Semi-structured proforma was then filled for each patient.

An Institutional Review Board (IRB) approval was taken prior to starting the study.

\section{Scales Used:}

Bradford Somatic Inventory (BSI): The Bradford Somatic Inventory is a multi-ethnic inventory of FSS associated with anxiety and depression. It has 46 items which enquires about the FSS during the previous month and, if the subject has experienced a particular symptom, whether the symptom has occurred on more or fewer than 15 days during the month (scoring 2 or 1, respectively). Based on the total score, FSS are categorized into 3 grades (a score $>40$ is considered to be the 'high' range, 26-40 'middle' range, and 0-25 'low' range) [12].

Beck's Depression Inventory (BDI): It was used to assess the severity of depression. It has 21 items, which describe a specific behavioural manifestation of depression which is rated on a graded series of 4-5 evaluation statements. BDI has been shown to have good internal consistency, test-retest and split half reliability [13]. 
Comprehensive Psychopathological Rating Scale-Anxiety Index (CPRS-AI): This was used to assess the level of anxiety. It comprises 7 items, each rated on a 4 points scale of varying from 0 to 3 [14].

\section{STATISTICAL ANALYSIS}

Descriptive analysis in terms of mean and standard deviation with range for continuous variables and frequency with percentage for ordinal and nominal variables was computed. Correlations between the variables were assessed using Pearson's product moment and Spearman's rank order correlation. Statistical analysis done by Chi-square test, t-test and ANOVA using SPSS version 20.

\section{RESULTS}

The mean age of the patients was 41.36 years, $21-40$ years (48\%) and $41-60$ years (52\%). There were more female patients compared to male, most were married, living in urban area, belonged to nuclear families. FSSs were more in working skilled worker and those earning < 2935 Indian rupees. It was more in graduates and post high school or diploma achievers and most of the patients (38\%) had moderate to severe depression as per BDI and slightly more than (26\%) had very severe depression. The mean duration of illness was 36 months. The most common depressive symptoms were loss of interest (96\%), followed by fatigue or tiredness (92\%) and sadness (88\%). The mean CPRS-AI score was 8.78 (SD-4.46). Aches and pains (94\%) were the most common anxiety symptoms followed by inner tension (84\%). The more commonly reported FSSs were severe headache (88\%), feeling tired when not working ( $86 \%$ ), lack of energy (weakness) much of the time (84\%). More common FSSs reported more than 15 days were lack of energy much of the time (68\%), feeling tired, even when not working (62\%), aches and pains all over the body (54\%). As per BSI 55\% more then 10 FSSs, with $30 \%$ having more than 20 FSSs. Those with very severe depression had significantly higher anxiety scores.

Table 1: Socio-demographic data of the population

\begin{tabular}{|c|c|c|}
\hline Variable & Category & $\mathbf{N ~ ( \% )}$ \\
\hline Mean Age in years & & $41.36 \pm 12.79$ years \\
\hline \multirow{4}{*}{ Age groups } & $21-30$ years & $11(22)$ \\
\cline { 2 - 3 } & $31-40$ years & $13(26)$ \\
\cline { 2 - 3 } & $41-50$ years & $16(32)$ \\
\cline { 2 - 3 } & $51-60$ years & $10(20)$ \\
\cline { 2 - 3 } Gender & Male & $20(40)$ \\
\hline \multirow{4}{*}{ Marital status } & Female & $30(60)$ \\
\cline { 2 - 3 } Family Type & Single & $4(8)$ \\
\cline { 2 - 3 } & Married & $42(84)$ \\
\cline { 2 - 3 } Religion & Divorced/widow & $4(8)$ \\
\hline \multirow{3}{*}{ Locality } & Nuclear & $29(58)$ \\
\cline { 2 - 3 } & Non-nuclear & $21(42)$ \\
\hline \multirow{4}{*}{ Occupation } & Hindu & $46(92)$ \\
\hline & Islam & $4(8)$ \\
\cline { 2 - 3 } & Urban & $38(76)$ \\
\cline { 2 - 3 } & Rural & $12(24)$ \\
\cline { 2 - 3 } & Unemployed & $2(14)$ \\
\cline { 2 - 3 } & Unskilled & $5(10)$ \\
\cline { 2 - 3 } & Semi-skilled & $23(46)$ \\
\cline { 2 - 3 } & Skilled & $3(6)$ \\
\cline { 2 - 3 } & Semi-professional/professional & $10(20)$ \\
\hline \multirow{3}{*}{ Education in years } & up to primary & $6(12)$ \\
\cline { 2 - 3 } & Up to middle school & $5(10)$ \\
\cline { 2 - 3 } & Up to high school & $9(18)$ \\
\hline
\end{tabular}




\begin{tabular}{|c|c|c|}
\hline \multirow{4}{*}{ Income in rupees } & Intermediate, high school/diploma & $11(22)$ \\
\cline { 2 - 3 } & Graduate/ post graduate & $11(22)$ \\
\cline { 2 - 3 } & Professional & $8(16)$ \\
\cline { 2 - 3 } & $0-2935$ & $22(44)$ \\
\cline { 2 - 3 } & $2936-4893$ & $10(20)$ \\
\cline { 2 - 3 } & $4894-7322$ & $8(16)$ \\
\cline { 2 - 3 } & $7323-9797$ & $4(8)$ \\
\cline { 2 - 3 } & $9788-19574$ & $6(12)$ \\
\cline { 2 - 3 }
\end{tabular}

Table 2: Descriptive statistics of individual FSSs as per Bradford Somatic Inventory

\begin{tabular}{|c|c|c|c|}
\hline BSI Items & Absent N (\%) & $\begin{array}{l}\text { Present }<15 \text { days in last } \\
\text { month N (\%) }\end{array}$ & $\begin{array}{l}\text { Present }>15 \text { days in last } \\
\text { month } N(\%)\end{array}$ \\
\hline Severe headaches & $6(12)$ & $19(38)$ & $25(50)$ \\
\hline $\begin{array}{l}\text { Fluttering or a feeling of something } \\
\text { moving in stomach }\end{array}$ & $33(66)$ & $7(14)$ & $10(20)$ \\
\hline $\begin{array}{c}\text { Pain or tension in neck and } \\
\text { shoulders }\end{array}$ & $17(34)$ & $13(26)$ & $20(40)$ \\
\hline Burning or itching all over the skin & $38(76)$ & $6(12)$ & $6(12)$ \\
\hline $\begin{array}{c}\text { Feeling of constriction of head, as if } \\
\text { it was being gripped tightly from } \\
\text { outside }\end{array}$ & $25(50)$ & $13(26)$ & $12(24)$ \\
\hline Pain in the chest or heart & $25(50)$ & $15(30)$ & $10(20)$ \\
\hline Mouth or throat getting dry & $14(28)$ & $17(34)$ & $19(38)$ \\
\hline Darkness or mist in front of eyes & $21(42)$ & $15(30)$ & $14(28)$ \\
\hline Burning sensation in stomach & $31(62)$ & $8(16)$ & $11(22)$ \\
\hline $\begin{array}{l}\text { Lack of energy (weakness) much of } \\
\text { the time }\end{array}$ & $8(16)$ & $8(16)$ & $34(68)$ \\
\hline Head feeling hot or burning & $16(32)$ & $14(28)$ & $20(40)$ \\
\hline Sweating a lot & $18(36)$ & $18(36)$ & $14(28)$ \\
\hline Pressure or tightness on chest & $31(62)$ & $14(28)$ & $5(10)$ \\
\hline Aches and pains in the abdomen & $30(60)$ & $11(22)$ & $9(18)$ \\
\hline Choking sensation in throat & $43(86)$ & $5(10)$ & $2(4)$ \\
\hline Hands and feet had pins and needles & $28(56)$ & $14(28)$ & $8(16)$ \\
\hline Aches and pains all over the body & $14(28)$ & $9(18)$ & $27(54)$ \\
\hline Feeling of heat inside body & $23(46)$ & $18(36)$ & $9(18)$ \\
\hline $\begin{array}{c}\text { Aware of palpitations (heart } \\
\text { pounding) }\end{array}$ & $21(42)$ & $19(38)$ & $10(20)$ \\
\hline Pain or burning in your eyes & $28(56)$ & $18(36)$ & $6(12)$ \\
\hline Suffering from indigestion & $23(46)$ & $14(28)$ & $13(26)$ \\
\hline Trembling or shaking & $21(42)$ & $15(30)$ & $14(28)$ \\
\hline Passing urine more frequently & $34(68)$ & $9(18)$ & $7(14)$ \\
\hline Low back trouble & $17(34)$ & $12(24)$ & $21(42)$ \\
\hline Stomach feeling swollen or bloated & $29(58)$ & $11(22)$ & $10(20)$ \\
\hline Head feeling heavy & $15(30)$ & $10(20)$ & $25(50)$ \\
\hline $\begin{array}{l}\text { Feeling tired, even when not } \\
\text { working }\end{array}$ & $7(14)$ & $12(24)$ & $31(62)$ \\
\hline Pain in legs & $9(18)$ & $14(28)$ & $27(54)$ \\
\hline Feeling sickin the stomach (nausea) & $23(26)$ & $18(36)$ & $9(18)$ \\
\hline Constipation & $23(46)$ & $15(30)$ & $12(24)$ \\
\hline $\begin{array}{c}\text { Difficulty in breathing, even when } \\
\text { resting }\end{array}$ & $30(60)$ & $13(26)$ & $7(14)$ \\
\hline $\begin{array}{l}\text { Feeling tingling (pins and needles) } \\
\text { all over the body }\end{array}$ & $38(76)$ & $6(12)$ & $6(12)$ \\
\hline $\begin{array}{l}\text { Feeling of pressure inside head, as } \\
\text { if head was going to burst }\end{array}$ & $29(58)$ & $10(20)$ & $11(22)$ \\
\hline
\end{tabular}




\begin{tabular}{|c|c|c|c|}
\hline $\begin{array}{c}\text { Wanting to open bowels more often } \\
\text { than usual }\end{array}$ & $39(78)$ & $9(18)$ & $2(4)$ \\
\hline Palms sweating a lot & $33(66)$ & $11(22)$ & $6(12)$ \\
\hline $\begin{array}{c}\text { Difficulty in swallowing, as if there } \\
\text { was a lump in throat }\end{array}$ & $39(78)$ & $8(16)$ & $3(6)$ \\
\hline Feeling giddy or dizzy & $20(40)$ & $20(40)$ & $10(20)$ \\
\hline Bitter taste in mouth & $33(66)$ & $10(20)$ & $7(14)$ \\
\hline Whole body feeling heavy & $21(42)$ & $13(26)$ & $4(8)$ \\
\hline $\begin{array}{c}\text { Burning sensation when passing } \\
\text { urine }\end{array}$ & $38(76)$ & $8(16)$ & $2(4)$ \\
\hline $\begin{array}{c}\text { Hearing a buzzing noise in ears or } \\
\text { head }\end{array}$ & $41(82)$ & $7(14)$ & $4(8)$ \\
\hline Heart feeling weak or sinking & $35(70)$ & $11(22)$ & $15(30)$ \\
\hline $\begin{array}{c}\text { Suffering from excessive wind (gas) } \\
\text { or belching }\end{array}$ & $28(56)$ & $17(34)$ & $1(8)$ \\
\hline Hands or feet feeling cold & $39(78)$ & $7(14)$ & $1(5)$ \\
\hline $\begin{array}{c}\text { Difficulty getting full Erection } \\
\text { (men only) }\end{array}$ & $17(85)$ & $2(10)$ & $3(15)$ \\
\hline $\begin{array}{c}\text { Feeling of passing semen in urine } \\
\text { (men only) }\end{array}$ & $16(80)$ & & \\
\hline
\end{tabular}

Table 3: Rating of the Participants as per Beck's Depression Inventory (BDI)

\begin{tabular}{|c|c|c|}
\hline BDI variables & Mean (SD) & Present frequency N ( $\%$ ) \\
\hline Sadness & $1.36(0.83)$ & $44(88)$ \\
\hline Pessimism & $1.10(0.86)$ & $38(76)$ \\
\hline Past failure & $1.10(0.81)$ & $39(78)$ \\
\hline Loss of pleasure & $1.06(0.74)$ & $40(80)$ \\
\hline Guilty feelings & $0.90(0.86)$ & $31(62)$ \\
\hline Punishment feelings & $0.88(0.82)$ & $33(66)$ \\
\hline Self-dislike & $0.86(0.73)$ & $34(68)$ \\
\hline Self-criticalness & $0.80(0.83)$ & $29(58)$ \\
\hline Suicidal thought and wishes & $0.62(0.83)$ & $23(46)$ \\
\hline Crying & $0.88(0.85)$ & $33(66)$ \\
\hline Irritability & $1.18(0.85)$ & $40(80)$ \\
\hline Loss of interest & $1.54(0.76)$ & $48(96)$ \\
\hline Indecisiveness & $1.34(0.89)$ & $42(84)$ \\
\hline Body image & $0.90(0.71)$ & $35(70)$ \\
\hline Loss of energy & $1.26(0.89)$ & $41(82)$ \\
\hline Change of sleep & $1.26(0.96)$ & $38(76)$ \\
\hline Tiredness or fatigue & $1.36(0.75)$ & $46(92)$ \\
\hline Change of appetite & $1.04(0.75)$ & $38(76)$ \\
\hline Weight loss & $0.94(0.89)$ & $32(64)$ \\
\hline Hypochondriasis & $1.20(0.78)$ & $42(84)$ \\
\hline Loss of interest in sex & $0.72(0.83)$ & $25(50)$ \\
\hline Total BDI Score & $22.3(17.22)$ & $18(36)$ \\
\hline \multirow{3}{*}{ Severity of Depression as per } & $10-16($ Mild) & $19(38)$ \\
\cline { 2 - 3 } BDI Scores & $17-29$ & $13(26)$ \\
\cline { 2 - 3 } & (moderate to severe) & \\
\cline { 2 - 3 } & $30-63($ very severe) & \\
\hline
\end{tabular}

\section{DISCUSSION}

Gender distribution was (female - 60\% vs. males $40 \%$ ) in Our study which is different from other study from India ${ }^{[1]]}$. Majority of the patients were married (84\%), Hindus (92\%), and from nuclear family (58\%). A more than half of the patients were from urban background ( $76 \%)$ this is quite different from other study [11]. The 
mean duration of illness at the time of assessment was 36 months. As per BDI severity score $36 \%$ have mild, $38 \%$ have moderate \& $26 \%$ have severe depression. Total mean CPRS-AI is $(8.78 \pm 4.46)$ approximately similar to earlier study. ${ }^{[13]}$ The morecommon FSS as assessed on Bradford Somatic Inventory were severe headache $(88 \%)$, feeling tired when not working $(86 \%)$, lack of energy (weakness) much of the time (84\%), pain in legs $(82 \%)$, aches and pains all over the body $(72 \%)$, mouth or throat getting dry $(72 \%)$, head feeling heavy $(70 \%)$, head feeling hot or burning $(68 \%)$, pain or tension in neck and shoulder $(66 \%)$, low back trouble $(66 \%)$ and sweating a lot (64\%). This profile of FSS is quite similar to that reported in an earlier study from India which evaluated FSS using BSI in a small sample size [11,13].

Table 4: Scores on the Comprehensive Psychopathological Rating Scale - Anxiety Index

\begin{tabular}{|c|c|c|}
\hline Variable & Mean (SD) & N (\%) \\
\hline Inner tension & $1.71(1.08)$ & $42(84)$ \\
\hline Hypochondriasis & $0.56(0.91)$ & $17(34)$ \\
\hline Phobias & $0.58(0.81)$ & $20(40)$ \\
\hline Autonomic disturbances & $1.18(0.96)$ & $36(72)$ \\
\hline Aches and pains & $2.18(1.00)$ & $47(94)$ \\
\hline Muscular tension & $1.50(0.97)$ & $39(78)$ \\
\hline Muscular tension observed & $1.10(0.81)$ & $39(78)$ \\
\hline Total mean CPRS-AI scores & $8.78(4.46)$ & \\
\hline
\end{tabular}

Table 5: Relationship of severity of depression with comprehensive psychopathological rating scaleanxiety index

\begin{tabular}{|c|c|c|}
\hline BDI Ranges & Total BSI score & Total CPRS-AI score \\
\hline $10-18$ (mild) & $20.61 \pm 10.37$ & $5.89 \pm 4.31$ \\
\hline 19-29 (moderate to severe) & $36.11 \pm 12.83$ & $8.95 \pm 2.70$ \\
\hline $30-63$ (very severe) & $43.00 \pm 17.59$ & $12.54 \pm 4.03$ \\
\hline ANOVA (Analysis of variance) & $11.67(\mathrm{p}<0.001)$ & $12.250(\mathrm{p}<0.001)$ \\
\hline
\end{tabular}

The prevalence and typology of FSS is to a certain extent influenced by the socio-demographic variables and severity of depression. This suggest that many FSS are present in patients with depression, which are specifically not included in the nosological systems and these FSS are present across different cultures and different treatment settings. Current clinical systems DSM-5 and ICD- 10 include FSS like feeling tired, having low energy and trouble sleeping as part of the diagnostic criteria of depression [15-17]. Furthermore, the findings of the study also suggest that clinicians should routinely look for FSS while assessing patients with depression and various clinical trials should also take these complaints into account while evaluating the efficacy of various antidepressants in patients of depression. With regard to clinical variables, it was seen that the severity and number of total FSS had positive correlation with severity of depression as assessed by BDI and CPRS-AI. Correlations between FSS, especially painful symptoms and severity of depression and anxiety, have been reported in various studies across the globe. However, few studies conducted in different treatment settings do not support the positive association between severity of depression and prevalence of FSS [18-23]. There is more evidence to suggest the positive association between prevalence of FSS and severity of depression. Hence, the association of severity and number of FSS with severity of depression and anxiety suggests that these symptoms are part and parcel of depression. Socio-demographic finding of higher prevalence of FSS in females [15] have been reported in an earlier study from India, whereas other studies have reported higher prevalence in males [24-25]. In the present study, patients from urban background had significantly higher BSI total score and higher number of total BSI symptoms, compared to those from the rural background. These findings suggest that the manifestation of depression is to a certain extent influenced by the locality of residence. In the present study, there was no significant difference in the number of FSS and severity of FSS between those educated less than high school and those educated up to or beyond high school. This is contradictory to the studies from the West. Presence of higher number of FSS in those from lower socioeconomic status is supported by findings from the West [23, 26-27]. Different Studies from the West, which have evaluated FSS using different instruments like somatic symptom inventory (SSI) and Self report 
90 item symptom checklist, and PHQ-15 have also reported high prevalence of different painful symptoms as similar to our study [29-32].

\section{CONCLUSIONS}

In our study, MDD (moderate to very severe) was diagnosed in $64 \%$ of participants \& Anxiety was found in $58 \%$ of participants. We should not ignore FSS when patient presents to consultants. Depression is found in many patients complaining of FSS, so they should be evaluated for depression and anxiety so that treatment can be started earlier. We need to train family physicians, PHC Doctors, CHC Doctors about common psychiatric disorders which presents with FSS so they can identify these patients and reference if needed can be done to tertiary level. In view of the high prevalence of FSS in depression, it is important to include these symptoms in the diagnostic criteria of depression, so as to increase the sensitivity and specificity of the diagnosis. The present study in the form of cross-sectional design and lack of assessment of other clinical correlates of depression. Statistical power is limited by the small sample size. Studying the topic with bigger sample size of the study may increase the statistical power. More aspects of functional somatic complaints may be studied for a more comprehensive view. The study was also limited to only treatment seeking patients attending the mental healthcare facilities. This study was conducted in a hospital sample. The study may be replicated in a community setting for a more accurate representation of Functional Somatic Symptoms in those are diagnosed as having major depressive disorders in general population as well. Relationship of FSS with treatment adherence, drug compliance and help- seeking behaviour was not studied.

\section{REFERENCES}

1. Mumford DB, Devereux TA, Maddy PJ, Johnston JV. Factors leading to the reporting of 'functional' somatic symptoms by general practice attenders. Br J Gen Pract 1991;352:454-8.

2. Peveler R, Kilkenny L, Kinmonth AL. Medically unexplained physical symptoms in primary care. A comparison of self-report screening questionnaires and clinical opinion. J Psychosom Res 1997;42:245-52.

3. Hanel G, Henningsen P, Herzog W, Sauer N, Schaefert R, Szecsenyi J, Löwe B. Depression, anxiety, and somatoform disorders: vague or distinct categories in primary care? Results from a large cross-sectional study. J Psychosom Res 2009;67:189-97.

4. Dirkwager AJ, Verhaak PF. Patients with persistent medically unexplained symptoms in general practice: characteristics and quality of care. BMC Fam Prac 2007;31:33-42.

5. Ohayon MM, Schatzberg AF. Using chronic pain to predict depressive morbidity in the general population. Arch Gen Psychiatry 2003;60:39-47.

6. Lieb R, Meinlschmidt G, Araya R. The association between somatoform disorders and anxiety and depressive disorders: an update. Psychosom Med 2007;69:860-3.

7. Kirmayer LJ, Robbins JM, Dworkind M, Yaffe MJ. Somatization and the recognition of depression and anxiety in primary care. Am J Psychiatry 1993;150:734-41.

8. Stegenga BT, Kamphuis MH, King M, Nazareth I, Geerlings MI. The natural course and outcome of major depressive disorder in primary care: the PREDICT-NL study. Soc Psychiatry Psychiatr Epidemiol 2012;47:8795.

9. Huijbregts KML, van der Feltz-Cornelis CM, van Marwijk HWJ, de Jong FJ, van der Windt DAWM, Beekman ATF. Negative association of concomitant physical symptoms with the course of major depressive disorder: a systematic review. J Psychosom Res 2010;68:511-9.

10. Papakostas GI, Petersen T, Denninger J, Sonawalla SB, Mahal Y, Alpert JE, Nierenberg AA, Fava M. Somatic symptoms in treatment-resistant depression. Psychiatry Res 2003;118:39-45.

11. Grover S, Avasthi A, Kalita K, Dalal P K, Rao G P, Chadda R K, Lakdawala B, Bang G, Chakraborty K, Kumar S, Singh P K, Kathuria P, Thirunavukarasu M, Sharma P, Harish T, Shah N, Deka K. IPS multicentric study: Functional somatic symptoms in depression. Indian J Psychiatry 2013;55:31-40

12. Mumford DB, Bavington JT, Bhatnagar KS, Hussain Y, Mirza S, Naraghi MM. The Bradford Somatic Inventory: A multi-ethnic inventory of somatic symptoms reported by anxious and depressed patients in Britain and the Indo-Pakistan subcontinent. Br J Psychiatry 1991;158(3):379-86.

13. Kendall PC, Hollon SD, Beck AT, Hammen CL, Ingram RE. Issues and recommendations regarding use of the Beck Depression Inventory. Cogn Ther Res 1987;11(3):289-99.

14. Svanborg P, Åsberg M. A new self-rating scale for depression and anxiety states based on the Comprehensive Psychopathological Rating Scale. Acta Psychiatr Scand 1994;89(1):21-8. 
15. Ang QQ, Wing YK, He Y, Sulaiman AH, Chiu NY, Shen YC, Wang G, Zhang C, Lee KH, Singh P, Granger RE, Raskin J, Dossenbach M. Association between painful physical symptoms and clinical outcomes in East Asian patients with major depressive disorder: a 3-month prospective observational study. Int J Clin Pract 2009;63:1041-9.

16. Posse M, Hallstrom T. Depressive disorders among somatizing patients in primary health care. Acta Psychiatr Scand 1998;98:187-92.

17. Chakraborty K, Avasthi A, Kumar S, Grover S. Psychological and clinical correlates of functional somatic complaints in depression. Int J Soc Psychiatry 2012;58:87-95.

18. Grover S, Kumar V, Chakrabarti S, Hollikatti P, Singh P, Tyagi S, et al. Prevalence and type of functional somatic symptoms in patients with first episode depression. East Asian Archives Psychiatry 2012;22:146-53.

19. Gautam SK, Kapur RL. Psychiatric patients with somatic complaints. Indian J Psychiatry 1977;19:75-80.

20. Westermeyer J. Psychiatric epidemiology across cultures: Current issues and trends. Transcultural Psychiatric Research Review 1989;26:5-25.

21. Haug TT, Mykletun A, Dahl AA. The association between anxiety, depression, and somatic symptoms in a large population: The HUNT-II study. Psychosom Med 2004;66:845-51.

22. Fink P, Ewald H, Jensen J, Sørensen L, Engberg M, Holm M, et al. Screening for somatization and hypochondriasis in primary care and neurological inpatients: A seven- item scale for hypochondriasis and somatization. J Psychosom Res 1999;46:261-73.

23. Kroenke K, Price R. Symptoms in the community. Prevalence, classification and psychiatric comorbidity. Arch Inten Med 1993;153:2474-80.

24. Kroenke K, Spitzer RL. Gender differences in the reporting of physical and somatoform symptoms. Psychosom Med 1998;60:150-5.

25. Srinivasan K, Srinivasa Murthy R, Janakiramaiah N. A nosological study of patients presenting with somatic complaints. Acta Psychiatr Scand 1986;73:1-5.

26. Banerjee G, Sinha S, Mukherjee DG, Sen G. A study of psychiatric disorders other than psychosis in the referred cases with somatic complaints. Indian J Psychiatry 1987;29:363-6.

27. Stewart DE. Physical symptoms of depression: Unmet needs in special populations. J Clin Psychiatry 2003;64(Supp1 7):12-6.

28. Wool CA, Barsky AJ. Do women somatize more than men? Gender differences in somatization. Psychosomatics 1994;35:445-52.

29. Vaccarino AL, Stills TL, Evans KR, Kalali AH. Prevalence and association of somatic symptoms in patients with Major Depressive Disorder. J Affect Disord 2008;110:270-6

30. Muñoz RA, McBride ME, Brnabic AJ, López CJ, Hetem LA, Secin R, et al. Major depressive disorder in Latin America: The relationship between depression severity, painful somatic symptoms, and quality of life. $\mathrm{J}$ Affect Disord 2005;86:93-8.

31. Sugahara H, Akamine M, Kondo T, Fujisawa K, Yoshimasu K, Tokunaga S, et al. Somatic symptoms most often associated with depression in an urban hospital medical setting in Japan. Psychiatry Res 2004;126:1518.

32. Corruble E, Guelfi JD. Pain complaints in depressed inpatients. Psychopathology 2000;33:307-9.

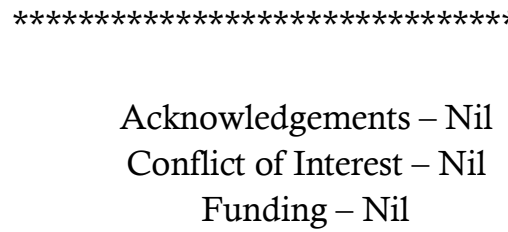

